\title{
Association between $\beta$-blocker use and mortality in critically ill patients: a nested cohort study
}

\author{
Shmeylan A. Al Harbi' ${ }^{1}$ Khalid A. Al Sulaiman ${ }^{1}$, Hani Tamim², ${ }^{1}$, Hasan M. Al-Dorzi ${ }^{3}$, Musharaf Sadat ${ }^{3}$
}

and Yaseen $\mathrm{Arabi}^{3^{*}}$ (1)

\begin{abstract}
Background: $\beta$-blockers have several indications in critically ill patients and are commonly used. The aim of this study is to examine the relationship between the use of $\beta$-blockers in critically ill patients and mortality.

Methods: This was a nested cohort study in which all medical-surgical ICU patients $(N=523)$ enrolled in a randomized clinical trial of intensive insulin therapy (ISRCTN07413772) were grouped according to $\beta$-blocker use during ICU stay. To account for the indication of $\beta$-blockers, we constructed a propensity score using selected clinically-relevant and statistically-significant variables related to $\beta$-blocker exposure and outcome. The primary endpoints were all-cause ICU and hospital mortality. Secondary endpoints were the development of severe sepsis during ICU stay, ICU and hospital length of stay, and mechanical ventilation duration. Using multivariable models, we adjusted the associations of $\beta$-blockers and these outcomes to the propensity score.
\end{abstract}

Results: Of the 523 patients enrolled in the study, 89 (17.0\%) received $\beta$-blockers during their ICU stay. There were no significant associations between $\beta$-blocker therapy and ICU mortality (adjusted odds ratio [aOR] 1.56, 95\% confidence interval $[\mathrm{Cl}] 0.83-2.9, P=0.16$ ), hospital mortality (aOR 1.09, 95\% Cl 0.99-1.20, $P=0.73$ ), the risk of ICU-acquired severe sepsis (aOR 1.67, 95\% Cl 0.95-2.97, $P=0.08$ ), mechanical ventilation duration $(P=0.17)$, or ICU length of stay $(P=0.22)$. However, $\beta$-blocker use was associated with increased ICU and hospital mortality among nondiabetic patients (aOR 2.93, 95\% Cl 1.19-7.23, and 2.43, 95\% Cl 1.05-5.64, respectively).

Conclusions: Our study showed that $\beta$-blockers during the ICU stay had no significant association with mortality or morbidity. However, $\beta$-blocker therapy was associated with increased mortality in non-diabetic patients.

Trial registration: ISRCTN07413772; (dated 13.07.2005).

Keywords: $\beta$-blockers, Mortality, Sepsis, Critically ill, Intensive care, Saudi Arabia

\section{Background}

$\beta$-blockers have many uses in critically ill patients. In many patients, $\beta$-blockers are used as a continuation of outpatient therapy for hypertension or cardiac indications. $\beta$-blockers are also initiated in the ICU for the management of different cardiovascular disorders and for reduction of myocardial re-infarction risk and its related

\footnotetext{
* Correspondence: arabi@ngha.med.sa

${ }^{3}$ Intensive Care Department, MC 1425, King Abdulaziz Medical City - National Guard Health Affairs, King Saud bin Abdulaziz University for Health Sciences, King Abdullah International Medical Research Center, PO Box 22490, Riyadh 1426, Kingdom of Saudi Arabia

Full list of author information is available at the end of the article
}

mortality [1-3]. In early sepsis, $\beta$-adrenergic receptors are stimulated leading to increase in the myocardial contractility and heart rate to meet metabolic demands, but in severe cases of septic shock, cardiac depression with impaired ejection fraction and myocardial cell necrosis may occurs and is associated with increased mortality [4]. In such cases, $\beta$-blockers may reduce the deleterious effects of $\beta$-adrenergic receptor stimulation [2] and have been proposed to be used to decrease the hypermetabolic state during sepsis in general $[5,6]$. However, data are limited regarding the efficacy of $\beta$-blockers in reducing mortality in critically ill patients [7].

(C) The Author(s). 2018 Open Access This article is distributed under the terms of the Creative Commons Attribution 4.0 International License (http://creativecommons.org/licenses/by/4.0/), which permits unrestricted use, distribution, and 


\section{Objectives}

This study aims to examine the relationship between use of $\beta$-blockers and mortality in medical-surgical-trauma critically ill patients.

\section{Methods}

\section{Study design}

This was a retrospective cohort study and post-hoc analysis of a randomized clinical trial (ISRCTN07413772) that was conducted between 2004 and 2006 and aimed to examine the effect of intensive insulin therapy on mortality in 523 medical-surgical ICU patients $[8,9]$. The study was approved by King Abdullah International Medical Research Center Institutional Review Board, Riyadh, Saudi Arabia.

\section{Setting}

This study was conducted in the adult medical-surgical ICU at King Abdulaziz Medical City, which is a tertiarycare academic referral hospital in Riyadh, Saudi Arabia. The ICU admits medical, surgical, and trauma patients, and operates as a closed unit with $24 / 7$ onsite coverage by critical care board-certified intensivists. The nurse-to-patient ratio in the unit is approximately 1:1.2 [10]. In addition, clinical pharmacists are a part of the daily multidisciplinary rounds. Cardiac patients, including those admitted with ST elevation myocardial infraction are admitted to cardiac ICUs and are not included in this study.

\section{Participants}

Patients were enrolled in the trial if they were $\geq 18$-yearold with serum glucose level $>6.1 \mathrm{mmol} / \mathrm{L}(110 \mathrm{mg} / \mathrm{dL})$ as measured by the laboratory during the first $24 \mathrm{~h}$ of ICU admission and had an expected ICU length of stay $($ LOS $)>24 \mathrm{~h}$. Exclusion criteria included type I diabetes, diabetic ketoacidosis, pregnancy, "Do-Not-Resuscitate" status within $24 \mathrm{~h}$ of admission, terminal illness, admission to the ICU after cardiac arrest, seizures, liver transplantation and/or burn injury. All patients enrolled in the original trial were included in this analysis.

\section{$\beta$-blocker therapy}

Data about $\beta$-blocker use in the study patients were collected from the pharmaceutical care services database and was combined with the original trial database. $\beta$ blocker therapy was either a newly prescribed medication in the ICU as per the treating teams discretion (for acute coronary syndrome or other indications) or a continuation of pre-ICU prescription. Acknowledging that different $\beta$-blockers may not have the same effect, all $\beta$-blockers were combined together because of the relatively small sample size and an expected physiological group effect. We included both oral and intravenous $\beta$-blocker use. Table 1 presents the $\beta$-blocker agents used.
Table $1 \beta$-blockers used in the study

\begin{tabular}{lll}
\hline$\beta$-blocker therapy & Oral $\mathrm{n}(\%)^{\mathrm{a}}$ & IV n (\%) \\
\hline Metoprolol & $68(76.4)$ & 0 \\
Atenolol & $23(25.8)$ & 0 \\
Carvedilol & $1(1.1)$ & 0 \\
Labetolol & $1(1.1)$ & $12(13.5)$ \\
Sotalol & $1(1.1)$ & 0
\end{tabular}

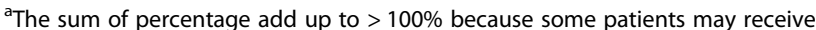
another $\beta$-blocker

\section{Data collection}

The following data were extracted from the original study: age, gender, admission category (non-operative, which included medical and trauma patients who did not require surgical interventions vs. post-operative), Acute Physiology and Chronic Health Evaluation (APACHE II) score [11], Sequential Organ Failure Assessment (SOFA) score [12] on the first day, chronic comorbidities (chronic liver disease, chronic cardiovascular disease, chronic respiratory disease, chronic renal disease and chronic immunosuppression) as defined by the APACHE II system, history of diabetes mellitus, and the presence of sepsis and severe sepsis on admission. In addition, statin and vasopressor use and serum creatinine level were documented. Estimated glomerular filtration rate (eGFR) was also calculated based on the Modification of Diet in Renal Disease equation [13].

\section{Outcomes}

The primary outcome was all-cause ICU mortality and hospital mortality. The secondary outcomes were the development of severe sepsis [14] during the ICU stay, mechanical ventilation duration and ICU and hospital length of stay.

\section{Statistical analysis}

There were two groups considered in this study, patients who received $\beta$-blockers during ICU admission ( $\beta$-blocker group) and patients who did not (non- $\beta$ blocker group). Baseline characteristics and outcome variables were compared between the two groups. Categorical variables were presented as number and percent, whereas continuous ones were presented as mean and standard deviation. Moreover, continuous variables were compared between the two groups by the Student t-test, while categorical ones were compared by the Chi-square test.

As expected in an observational study, differences in baseline characteristics between the two study groups may exist. To adjust for these differences, a propensity score for the use of $\beta$-blockers was generated with the following variables included: age, gender, diabetes 
history, admission category, APACHE II score, chronic disease (respiratory disease, renal disease, chronic immunosuppression), median estimated GFR, and statin use. Multivariate logistic regression analyses was used to assess the association between $\beta$-blockers and the different outcomes considered in this study, adjusting for the generated propensity score.

Furthermore, to identify effect modification by different variables on the association between $\beta$-blockers and outcomes, we carried out subgroup analyses by the following variables: age, gender, admission category, APACHE II, history of diabetes, the presence of chronic cardiac disease, vasopressor therapy, sepsis, severe sepsis and septic shock, estimated GFR, and statin therapy. For age, APACHE II and estimated GFR, categorization was based on the median values as cut off. A $p$-value for interaction was calculated using an interaction term in the multivariate models.

Finally, the odds ratios (OR) with the $95 \%$ confidence intervals $(\mathrm{CI})$ were reported for the associations.

All statistical analyses were carried out using the Statistical Analysis Software (SAS, release 9, SAS Institute, Cary, NC, 2005).

\section{Results}

\section{Patient characteristics}

Of the 523 patients enrolled in the study, 89 (17\%) received $\beta$-blockers during their ICU stay. Table 2 presents baseline characteristics between $\beta$-blocker and non- $\beta$ blocker group. Patients who received $\beta$-blockers were older, more likely to be males, had higher APACHE II scores, had higher serum creatinine, and were more likely to be on statins. When adjusted for propensity score, all these differences became insignificant.

\section{Outcomes}

The association between $\beta$-blocker therapy and mortality using multivariate analysis adjusted for propensity score is summarized in Table 3. There was no significant association between $\beta$-blocker therapy and ICU mortality (adjusted OR 1.56, 95\% CI 0.83-2.9, $P=0.16$ ), hospital mortality (adjusted OR 1.09, 95\% CI 0.99-1.20, $P=0.73$ ), risk of ICU-acquired severe sepsis (aOR 1.67, 95\% CI $0.95-2.97, P=0.08)$, mechanical ventilation duration $(P=0.17)$, and ICU length of stay $(P=0.22)$.

Table 4 shows the association between $\beta$-blocker therapy and all-cause hospital mortality in several subgroups

Table 2 Baseline characteristics of the $\beta$-blocker and Non- $\beta$-blocker therapy groups

\begin{tabular}{|c|c|c|c|c|}
\hline Variable & $\begin{array}{l}\beta \text {-blocker } \\
N=89\end{array}$ & $\begin{array}{l}\text { Non- } \beta \text {-blocker } \\
N=434\end{array}$ & $P$ value & PS $^{*}$ Adjusted $P$ Value \\
\hline Age (years) mean $\pm S D$ & $65.6 \pm 14.78$ & $49.7 \pm 21.88$ & $<0.0001$ & 0.37 \\
\hline \multicolumn{5}{|l|}{ Gender, n (\%) } \\
\hline Female & $35(39.3)$ & $97(22.4)$ & 0.0008 & 0.09 \\
\hline Male & $54(60.7)$ & $337(77.7)$ & & \\
\hline Diabetes, n (\%) & $61(68.5)$ & $147(33.9)$ & $<0.0001$ & 0.31 \\
\hline \multicolumn{5}{|l|}{ Admission category, n (\%) } \\
\hline Non-operative & $78(87.6)$ & $357(82.3)$ & 0.21 & 0.93 \\
\hline Post-operative & $11(12.4)$ & $77(17.7)$ & & \\
\hline APACHE II score, mean \pm SD & $24.9 \pm 8.01$ & $22.4 \pm 8.09$ & 0.008 & 0.48 \\
\hline SOFA score Day 1 , mean \pm SD & $8.7 \pm 3.65$ & $8.8 \pm 3.47$ & 0.97 & 0.22 \\
\hline Sepsis, n (\%) & $18(20.2)$ & $104(24.0)$ & 0.44 & 0.03 \\
\hline Septic Shock, n (\%) & $23(25.84)$ & $102(23.5)$ & 0.64 & 0.08 \\
\hline Chronic Respiratory disease, n (\%) & $10(11.2)$ & $60(13.8)$ & 0.51 & 0.05 \\
\hline Chronic Cardiac disease n (\%) & $24(27.0)$ & $53(12.2)$ & 0.0003 & 0.16 \\
\hline Chronic liver disease n (\%) & $10(11.2)$ & $26(6.0)$ & 0.07 & 0.05 \\
\hline Chronic immunosuppression, n (\%) & $9(10.1)$ & $38(8.8)$ & 0.68 & 0.89 \\
\hline Chronic renal disease, n (\%) & $14(15.7)$ & $41(9.5)$ & 0.07 & 0.60 \\
\hline Creatinine (micromol/L), mean \pm SD & $194.0 \pm 152.89$ & $148.8 \pm 143.10$ & 0.01 & 0.52 \\
\hline Estimated GFR, mean \pm SD & $77.3 \pm 62.8$ & $54.5 \pm 52.8$ & 0.001 & 0.57 \\
\hline Vasopressor, n (\%) & $55(61.8)$ & $286(65.9)$ & 0.45 & 0.64 \\
\hline Statin use, n (\%) & $34(38.2)$ & $34(7.8)$ & $<0.0001$ & 0.89 \\
\hline
\end{tabular}

APACHE Acute Physiology and Chronic Health Evaluation, SOFA Sequential Organ Failure Assessment, GFR glomerular filtration rate, PS propensity score *variables entered in propensity model are age, gender, diabetes history, admission category, APACHE II score, chronic disease (respiratory disease, renal disease, chronic immunosuppression), median estimated GFR, and statin use 
Table 3 Outcomes of the $\beta$-blockers and non- $\beta$-blocker therapy groups

\begin{tabular}{|c|c|c|c|c|c|c|}
\hline \multirow{3}{*}{ Variable } & \multicolumn{6}{|c|}{ Categorical Variables } \\
\hline & \multirow{2}{*}{$\begin{array}{l}\beta \text {-blocker } \\
N=89\end{array}$} & \multirow{2}{*}{$\begin{array}{l}\text { Non } \beta \text {-blocker } \\
N=434\end{array}$} & \multirow[t]{2}{*}{$P$ value } & \multicolumn{3}{|l|}{ Risk } \\
\hline & & & & $\mathrm{aOR}$ & $95 \% \mathrm{Cl}$ & $P$ value \\
\hline ICU Mortality, (n\%) & $18(20.2)$ & $62(14.3)$ & 0.16 & 1.56 & $0.83-2.9$ & 0.16 \\
\hline Hospital Mortality, (n\%) & $34(38.2)$ & $121(27.9)$ & 0.05 & 1.09 & $0.65,1.83$ & 0.73 \\
\hline 180-day mortality, (n\%) & $19(23.0)$ & $69(17.5)$ & 0.25 & 0.73 & $0.38-1.38$ & 0.33 \\
\hline Sepsis, (n\%) & $30(33.7)$ & $173(39.9)$ & 0.27 & 1.20 & $0.71-2.02$ & 0.49 \\
\hline \multirow[t]{3}{*}{ Severe Sepsis, (n\%) } & $23(25.8)$ & $102(23.5)$ & 0.63 & 1.68 & $0.95-2.97$ & 0.08 \\
\hline & \multicolumn{6}{|c|}{ Continuous Variables } \\
\hline & & & & Parameter estimate & $95 \% \mathrm{Cl}$ & $P$ value \\
\hline Mechanical ventilation duration (days), mean \pm SD & $10.5 \pm 13.3$ & $8.7 \pm 8.7$ & 0.11 & 2.66 & $0.34-4.99$ & 0.17 \\
\hline ICU LOS (days), mean \pm SD & $11.3 \pm 14.0$ & $10.0 \pm 8.9$ & 0.23 & 1.99 & $-0.43-4.41$ & 0.22 \\
\hline Hospital LOS (days), mean \pm SD & $59.5 \pm 101.9$ & $55.0 \pm 75.7$ & 0.63 & 7.95 & $-11.68-27.58$ & 0.34 \\
\hline
\end{tabular}

$a O R$ adjusted odds ratio, $\mathrm{Cl}$ confidence interval, ICU intensive care unit, LOS length of stay

of patients. The analysis showed $\beta$-blocker use was associated with increased ICU and hospital mortality among non-diabetic patients (aOR 2.93, 95\% CI 1.19-7.23, and 2.43, 95\% CI 1.05-5.64, respectively).

\section{Discussion}

Our study showed that pre-ICU continuation or initiation of $\beta$-blockers during the ICU stay in unselected critically ill patients was not associated with lower mortality or morbidity. $\beta$-blocker therapy was associated with increased mortality in non-diabetic patients.

By blocking the $\beta$-adrenergic receptors, $\beta$-blockers antagonize the effects of sympathetic nerve stimulation or circulating catecholamines [3]. Hence, they have many treatment indications and are commonly prescribed to reduce the risk of myocardial infarction and in the treatment of cardiovascular diseases, such as hypertension and congestive heart failure [1]. Additionally, they are frequently used in the general ICU setting. However, studies on $\beta$-blocker use in ICU patients varied considerably in design (retrospective or prospective cohorts, randomized controlled trials), patient population (sepsis, septic shock, postoperative), type and route of administration of $\beta$-blockers, timing of therapy (initiated pre-ICU or during ICU), target of therapy, duration of follow-up [2, 3, 7, 15-17]. As expected, these studies had different results.

Multiple studies demonstrated benefit of $\beta$-blocker use in ICU patients. Christensen et al. evaluated 8087 patients older than 45 years who were admitted to three ICUs in Northern Denmark between 1999 and 2005 and found that the pre-admission $\beta$-blocker use was associated with reduced 30-day mortality following ICU admission (OR 0.69, 95\% CI 0.54-0.88 for surgical patients and $0.71,95 \%$ CI $0.51-0.98)$ for medical patients [15].
Macchia et al. analyzed a database of Italian ICU patients hospitalized for sepsis and found a 28-day survival advantage in patients who were taking $\beta$-blockers at the time of admission and who subsequently developed sepsis compared with those untreated with it (OR 0.81, 95\% CI 0.68-0.97; $P=0.025$ ) [16]. Morelli et al. conducted the first randomized control trial in ICU patients with septic shock with a heart rate $\geq 95$ beats/min and requiring high-dose norepinephrine to maintain a mean arterial pressure $\geq 65 \mathrm{mmHg}$ and found that a continuous esmolol infusion, started $24 \mathrm{~h}$ post hemodynamic optimization and titrated to preserve the heart rate between 80 and 94 beats/min, was associated with 28-day mortality reduction and decrease in requirements of norepinephrine and fluid compared with standard care [2]. In addition, Noveanuet al. evaluated patients with acute respiratory failure who were admitted to ICU and found that oral $\beta$-blockers at admission were associated with a lower risk of both in-hospital (hazard ratio 0.33, 95\% CI 0.14-0.74) $P=0.007$ ) and one-year mortality (hazard ratio $0.29,95 \% \mathrm{CI} 0.16-0.51 ; P=0.0003$ ) [18]. In severe traumatic brain injury, $\beta$-blocker use has been associated with reduced mortality risk in multiple studies $[19,20]$. A retrospective cohort study in the United States, conducted between 2000 and 2001, found that perioperative $\beta$-blocker therapy among high-risk (revised Cardiac Risk Index score $\geq 2$ ) patients undergoing major non-cardiac surgery was associated with a reduced risk of in-hospital death (aOR for in-hospital death 0.88, 95\% CI 0.80-0.98) [21].

However, other studies found worse outcomes with $\beta$-blocker use in the ICU. The POISE trial found that patients receiving metoprolol succinate $2-4 \mathrm{~h}$ before surgery and continued for 30 days had an increased risk of stroke and death associated with an increased 
Table 4 Stratified analysis adjusted mortality

\begin{tabular}{|c|c|c|c|c|c|c|c|c|c|c|c|c|}
\hline \multirow[b]{2}{*}{ Variable } & \multicolumn{4}{|c|}{180 Day Mortality } & \multicolumn{4}{|c|}{ ICU Mortality } & \multicolumn{4}{|c|}{ Hospital Mortality } \\
\hline & $\mathrm{N}$ & $\mathrm{aOR}$ & $95 \% \mathrm{Cl}$ & $\begin{array}{l}P \text { value } \\
\text { for interaction }\end{array}$ & $\mathrm{N}$ & $\mathrm{aOR}$ & $95 \% \mathrm{Cl}$ & $\begin{array}{l}P \text { value } \\
\text { for interaction }\end{array}$ & $\mathrm{N}$ & $\mathrm{aOR}$ & $95 \% \mathrm{Cl}$ & $\begin{array}{l}P \text { value } \\
\text { for interaction }\end{array}$ \\
\hline \multicolumn{13}{|l|}{ Age (years) } \\
\hline Age $<58$ & 230 & 0.57 & $0.10-3.2$ & 0.58 & 263 & 1.89 & $0.56-6.4$ & 0.43 & 263 & 1.21 & $0.41-3.5$ & 0.27 \\
\hline Age $>58$ & 247 & 0.83 & $0.43-1.62$ & & 260 & 1.48 & $0.72-3.1$ & & 260 & 1.11 & $0.62-1.99$ & \\
\hline \multicolumn{13}{|l|}{ Gender } \\
\hline Male & 355 & 0.54 & $0.23-1.26$ & 0.57 & 391 & 1.72 & $0.80-3.68$ & 0.14 & 391 & 0.95 & $0.49-1.85$ & 0.82 \\
\hline Female & 122 & 1.45 & $0.52-4.1$ & & 132 & 1.30 & $0.44-3.88$ & & 132 & 1.45 & $0.62-3.39$ & \\
\hline \multicolumn{13}{|l|}{ Diabetes } \\
\hline Yes & 194 & 0.63 & $0.30-1.36$ & 0.07 & 208 & 0.93 & $0.40-2.17$ & 0.01 & 208 & 0.73 & $0.39-1.38$ & 0.002 \\
\hline No & 283 & 1.22 & $0.40-3.7$ & & 315 & 2.93 & $1.19-7.23$ & & 315 & 2.43 & $1.05-5.64$ & \\
\hline \multicolumn{13}{|l|}{ Vasopressors } \\
\hline Yes & 307 & 0.70 & $0.32-1.50$ & 0.36 & 341 & 1.86 & $0.89-3.89$ & 0.85 & 341 & 1.25 & $0.67-2.32$ & 0.84 \\
\hline No & 170 & 1.10 & $0.32-3.74$ & & 182 & 0.89 & $0.27-2.99$ & & 182 & 0.83 & $0.32-2.18$ & \\
\hline \multicolumn{13}{|l|}{ APACHE II score } \\
\hline$<23$ & 236 & 0.85 & $0.22-3.26$ & 0.32 & 271 & 2.22 & $0.66-7.48$ & 0.12 & 271 & 1.12 & $0.40-3.13$ & 0.23 \\
\hline$>23$ & 241 & 0.67 & $0.32-1.40$ & & 252 & 1.23 & $0.59-2.56$ & & 252 & 0.98 & $0.53-1.82$ & \\
\hline \multicolumn{13}{|l|}{ Sepsis } \\
\hline Yes & 117 & 0.83 & $0.24-2.95$ & 0.37 & 122 & 1.06 & $0.30-3.78$ & 0.12 & 122 & 0.92 & $0.32-2.63$ & 0.06 \\
\hline No & 360 & 0.71 & $0.33-1.51$ & & 401 & 1.91 & $0.90-4.08$ & & 401 & 1.26 & $0.70-2.37$ & \\
\hline \multicolumn{13}{|l|}{ Severe sepsis } \\
\hline Yes & 115 & 0.52 & $0.11-2.41$ & 0.71 & 125 & 0.73 & $0.25-2.09$ & 0.19 & 125 & 0.71 & $0.25-2.01$ & 0.72 \\
\hline No & 362 & 0.80 & $0.39-1.62$ & & 398 & 2.09 & $092-4.73$ & & 398 & 1.10 & $0.59-2.06$ & \\
\hline \multicolumn{13}{|c|}{ Admission category } \\
\hline Non-operative & 404 & 0.79 & $0.41-1.52$ & 0.92 & 435 & 1.50 & $0.78-2.90$ & 0.50 & 435 & 1.15 & $0.67-1.98$ & 0.81 \\
\hline Post-operative & 73 & 0.21 & $0.015-3.0$ & & 88 & 1.96 & $0.26-14.71$ & & 88 & 0.52 & $0.09-3.06$ & \\
\hline \multicolumn{13}{|c|}{ Chronic Respiratory Disease } \\
\hline Yes & 68 & 1.15 & $0.21-6.32$ & 0.85 & 70 & 4.89 & $1.18-20.30$ & 0.11 & 70 & 7.27 & $1.39-37.93$ & 0.06 \\
\hline No & 409 & 0.62 & $0.30,1.26$ & & 453 & 1.28 & $0.61-2.71$ & & 453 & 0.80 & $0.44-1.43$ & \\
\hline \multicolumn{13}{|c|}{ Chronic Renal disease } \\
\hline Yes & 53 & 1.22 & $0.33-4.5$ & 0.97 & 55 & 1.39 & $0.29-6.63$ & 0.69 & 55 & 0.82 & $0.24-2.77$ & 0.25 \\
\hline No & 424 & 0.60 & $0.28-1.27$ & & 468 & 1.55 & $0.78-3.09$ & & 468 & 1.10 & $0.62-1.96$ & \\
\hline \multicolumn{13}{|c|}{ Chronic Cardiac disease } \\
\hline Yes & 74 & 0.56 & $0.18-1.71$ & 0.13 & 77 & 0.69 & $0.19-2.48$ & 0.09 & 77 & 0.45 & $0.16-1.29$ & 0.003 \\
\hline No & 403 & 0.75 & $0.34-1.64$ & & 446 & 1.88 & $0.92-3.85$ & & 446 & 1.34 & $0.74-2.44$ & \\
\hline \multicolumn{13}{|c|}{ Estimated GFR (mL/min) } \\
\hline$\leq 73$ & 246 & 0.82 & $0.42-1.62$ & 0.23 & 261 & 1.02 & $0.50-2.05$ & 0.08 & 261 & 0.84 & $0.47-1.50$ & 0.06 \\
\hline$>73$ & 231 & 0.21 & $0.03-1.54$ & & 262 & 3.40 & $0.89-12.89$ & & 262 & 1.36 & $0.44-4.25$ & \\
\hline \multicolumn{13}{|l|}{ SOFA score } \\
\hline$\leq 9$ & 274 & 0.70 & $0.26-1.84$ & 0.56 & 305 & 1.39 & $0.51-3.79$ & 0.99 & 305 & 0.89 & $0.40-1.97$ & 0.90 \\
\hline$>9$ & 203 & 0.77 & $0.31-1.85$ & & 218 & 1.62 & $0.71-3.68$ & & 218 & 1.29 & $0.61-2.73$ & \\
\hline \multicolumn{13}{|c|}{ ICU duration (days) } \\
\hline$\leq 5$ & 231 & 0.74 & $0.28-1.92$ & 0.70 & 256 & 1.44 & $0.52-4.03$ & 0.51 & 256 & 1.07 & $0.46-2.47$ & 0.31 \\
\hline$>5$ & 246 & 0.70 & $0.29-1.71$ & & 267 & 1.60 & $0.71-3.58$ & & 267 & 1.06 & $0.50-2.25$ & \\
\hline
\end{tabular}


Table 4 Stratified analysis adjusted mortality (Continued)

\begin{tabular}{|c|c|c|c|c|c|c|c|c|c|c|c|c|}
\hline \multirow[b]{2}{*}{ Variable } & \multicolumn{4}{|c|}{180 Day Mortality } & \multicolumn{4}{|c|}{ ICU Mortality } & \multicolumn{4}{|c|}{ Hospital Mortality } \\
\hline & $N$ & $\mathrm{aOR}$ & $95 \% \mathrm{Cl}$ & $\begin{array}{l}P \text { value } \\
\text { for interaction }\end{array}$ & $\mathrm{N}$ & $\mathrm{aOR}$ & $95 \% \mathrm{Cl}$ & $\begin{array}{l}P \text { value } \\
\text { for interaction }\end{array}$ & N & $\mathrm{aOR}$ & $95 \% \mathrm{Cl}$ & $\begin{array}{l}P \text { value } \\
\text { for interaction }\end{array}$ \\
\hline \multicolumn{13}{|l|}{ Statin Use } \\
\hline Yes & 66 & 0.92 & $0.30-2.79$ & 0.86 & 68 & 0.46 & $0.10-2.10$ & 0.02 & 68 & 1.005 & $0.35-2.92$ & 0.19 \\
\hline No & 411 & 0.65 & $0.28-1.51$ & & 455 & 2.29 & $1.16-4.54$ & & 455 & 1.40 & $0.76-2.57$ & \\
\hline
\end{tabular}

aOR adjusted odds ratio, APACHE Acute Physiology and Chronic Health Evaluation, $\mathrm{Cl}$ confidence interval, GFR glomerular filtration rate, ICU intensive care unit, SOFA Sequential Organ Failure Assessment

incidence of hypotension, bradycardia (hazard ratio 2.17 , 95\% CI 1.26-3.74; $p=0.005$ ) and bleeding (hazard ratio 1.33, 95\% CI 1.03-1.74; $p=0.03$ ) [17]. In patients older than 65 years who suffered from trauma, those without head injury, pre-injury $\beta$-blocker use was associated with increased mortality (OR 2.1, 95\% CI 1.1-4.3) [22].

Our study found that $\beta$-blocker use was not associated with lower ICU mortality or hospital mortality in unselected ICU patients. Also, there was no obvious benefit in various patient subgroups, including diabetics. However, its use in non-diabetic patients was associated with increased mortality risk. $\beta$-blocker therapy among diabetic patients may have a beneficial effect. Wang et al. found that pre-operative $\beta$-blocker therapy shows a reduction in operative $(0.5 \%$ vs $6.0 \%, P=0.007)$ and 1 year mortality $(99.1 \%$ vs $88.1 \%$, log-rank $P=0.002)$ in patients undergoing coronary artery bypass grafting [23]. Another study by Tsujimoto et al. found a beneficial effect of $\beta$-blocker therapy in diabetic patients with history of myocardial infarction and reduced left ventricular ejection fraction (adjusted hazard ratio for all-cause mortality $0.60,95 \%$ CI $0.37-0.98 ; P=0.04$ ) [24].

The findings of our study must be interpreted in the light of its strengths and weaknesses. The strengths include being a nested cohort within a randomized controlled trial with prospective data collection. On the other hand, there are some limitations in our study, including the mono-center study nature, the small sample size and the post-hoc design analysis. Although we used propensity score account for confounders, unmeasured confounders cannot be entirely be excluded. Data on the duration and doses of $\beta$-blockers prior to ICU admission and on the cardiovascular parameters were not available. Additionally, we had no long-term follow-up of patients. Also, among the questions that need answers in future studies is whether the effect of $\beta$-blocker therapy on mortality in critically ill patients is a class effect or an individual $\beta$-blocker effect.

\section{Conclusions}

Our study showed that continuing or initiating $\beta$-blocker therapy during ICU stay was not associated with reduction in ICU or hospital mortality in unselected ICU population, but it may increase mortality in nondiabetic patients. These data confirm the need for randomized controlled trials with larger sample size to clarify the relationship between $\beta$-blocker treatment and the outcomes of critically ill patients.

\section{Abbreviations}

aOR: Adjusted odds ratio; APACHE: Acute Physiology and Chronic Health Evaluation; DKA: Diabetic ketoacidosis; eGFR: Estimated glomerular filtration rate; ICU: Intensive care unit; LOS: Length of stay; SOFA: Sequential Organ Failure Assessment

\section{Availability of data and materials}

The datasets used and/or analyzed during the current study are available from the corresponding author on reasonable request.

\section{Authors' contributions}

SAA: Conception and design, analysis and interpretation of data, drafting of the manuscript, critical revision of the manuscript for important intellectual content, supervision and final approval of the version to be published. KS: Analysis and interpretation of data, drafting of the manuscript, critical revision of the manuscript for important intellectual content and final approval of the version to be published. HMT: Analysis and interpretation of data, critical revision of the manuscript for important intellectual content and final approval of the version to be published. HMD: Analysis and interpretation of data, drafting of the manuscript, critical revision of the manuscript for important intellectual content and final approval of the version to be published. MS: Acquisition of data, critical revision of the manuscript for important intellectual content, and final approval of the version to be published. YMA: Acquisition of data, conception and design, analysis and interpretation of data, statistical analysis, critical revision of the manuscript and overall supervision.

\section{Ethics approval and consent to participate}

This study was approved by the King Abdullah International Medical Research Center (KAIMRC/ Ministry of National Guard Health Affairs- Institutional Review Board. The original trial was registered at ISRCTN and assigned the number ISRCTN07413772. The consent for the present analysis was waived because of the observational nature of the study.

\section{Competing interests}

The authors have no financial or non-financial competing interests to declare.

\section{Publisher's Note}

Springer Nature remains neutral with regard to jurisdictional claims in published maps and institutional affiliations.

\section{Author details}

${ }^{1}$ Pharmaceutical Care Department, King Abdulaziz Medical City, King Saud bin Abdulaziz University for Health Sciences, King Abdullah International Medical Research Center, Riyadh, Saudi Arabia. ${ }^{2}$ Department of Internal Medicine, American University of Beirut- Medical Center, Beirut, Lebanon. ${ }^{3}$ Intensive Care Department, MC 1425, King Abdulaziz Medical City - National Guard Health Affairs, King Saud bin Abdulaziz University for Health Sciences, King Abdullah International Medical Research Center, PO Box 22490, Riyadh 1426, Kingdom of Saudi Arabia. 
Received: 11 October 2017 Accepted: 30 April 2018

Published online: 16 May 2018

\section{References}

1. Sanfilippo F, Santonocito C, Foex P. Use of beta-blockers in non-cardiac surgery: an open debate. Minerva Anestesiol. 2014;80(4):482-94.

2. Morelli A, Ertmer C, Westphal M, Rehberg S, Kampmeier T, Ligges S, Orecchioni A, D'Egidio A, D'Ippoliti F, Raffone C, et al. Effect of heart rate control with esmolol on hemodynamic and clinical outcomes in patients with septic shock: a randomized clinical trial. JAMA. 2013;310(16):1683-91.

3. Coppola S, Froio S, Chiumello D. $\beta$-blockers in critically ill patients: from physiology to clinical evidence. Crit Care. 2015;19(1):119.

4. Vieillard-Baron A, Caille V, Charron C, Belliard G, Page B, Jardin F. Actual incidence of global left ventricular hypokinesia in adult septic shock. Crit Care Med. 2008;36(6):1701-6.

5. Novotny NM, Lahm T, Markel TA, Crisostomo PR, Wang M, Wang Y, Ray R, Tan J, Al-Azzawi D, Meldrum DR. Beta-blockers in sepsis: reexamining the evidence. Shock. 2009;31(2):113-9.

6. Ginsberg F. Beta-blockers: more good news? Crit Care Med. 2012;40(10):2901-2.

7. Chacko CJ, Gopal S. Systematic review of use of $\beta$-blockers in sepsis. J Anaesthesiol Clin Pharmacol. 2015;31(4):460-5.

8. Arabi YM, Dabbagh OC, Tamim HM, Al-Shimemeri AA, Memish ZA, Haddad SH, Syed SJ, Giridhar HR, Rishu AH, Al-Daker MO, et al. Intensive versus conventional insulin therapy: a randomized controlled trial in medical and surgical critically ill patients. Crit Care Med. 2008;36(12):3190-7.

9. Al Harbi SA, Tamim HM, Al-Dorzi HM, Sadat M, Arabi YM. Association between aspirin therapy and the outcome in critically ill patients: a nested cohort study. BMC Pharmacol Toxicol. 2016;17:5.

10. Arabi Y, Alshimemeri A, Taher S. Weekend and weeknight admissions have the same outcome of weekday admissions to an intensive care unit with onsite intensivist coverage. Crit Care Med. 2006;34(3):605-11.

11. Knaus WA, Draper EA, Wagner DP, Zimmerman JE. APACHE II: a severity of disease classification system. Crit Care Med. 1985;13(10):818-29.

12. Ferreira FL, Bota DP, Bross A, Melot C, Vincent JL. Serial evaluation of the SOFA score to predict outcome in critically ill patients. JAMA. 2001;286(14):1754-8.

13. Levey AS, Bosch JP, Lewis JB, Greene T, Rogers N, Roth D. A more accurate method to estimate glomerular filtration rate from serum creatinine: a new prediction equation. Modification of diet in renal disease study group. Ann Intern Med. 1999;130(6):461-70.

14. Levy MM, Fink MP, Marshall JC, Abraham E, Angus D, Cook D, Cohen J, Opal SM, Vincent J-L, Ramsay G. 2001 sccm/esicm/accp/ats/sis international sepsis definitions conference. Intensive Care Med. 2003;29(4):530-8.

15. Christensen $S$, Johansen MB, Tonnesen E, Larsson A, Pedersen L, Lemeshow S, Sorensen HT. Preadmission beta-blocker use and 30-day mortality among patients in intensive care: a cohort study. Crit Care. 2011;15(2):R87.

16. Macchia A, Romero M, Comignani PD, Mariani J, D'Ettorre A, Prini N, Santopinto M, Tognoni G. Previous prescription of beta-blockers is associated with reduced mortality among patients hospitalized in intensive care units for sepsis. Crit Care Med. 2012;40(10):2768-72.

17. Group PS, Devereaux PJ, Yang H, Yusuf S, Guyatt G, Leslie K, Villar JC, Xavier D, Chrolavicius S, Greenspan L, et al. Effects of extended-release metoprolol succinate in patients undergoing non-cardiac surgery (POISE trial): a randomised controlled trial. Lancet. 2008;371(9627):1839-47.

18. Noveanu M, Breidthardt T, Reichlin T, Gayat E, Potocki M, Pargger $H$, Heise A, Meissner J, Twerenbold R, Muravitskaya N, et al. Effect of oral betablocker on short and long-term mortality in patients with acute respiratory failure: results from the BASEL-II-ICU study. Critical Care. 2010;14(6):R198.

19. Cotton B, Snodgrass K, Fleming S, Carpenter R, Kemp C, Arbogast P, Morris J $J$ r. Beta-blocker exposure is associated with improved survival after severe traumatic brain injury. J Trauma. 2007;62(1):26.

20. Inaba K, Teixeira PG, David J-S, Chan LS, Salim A, Brown C, Browder T, Beale E, Rhee P, Demetriades D. Beta-blockers in isolated blunt head injury. J Am Coll Surg. 2008;206(3):432-8.

21. Lindenauer PK, Pekow P, Wang K, Mamidi DK, Gutierrez B, Benjamin EM Perioperative beta-blocker therapy and mortality after major noncardiac surgery. N Engl J Med. 2005;353(4):349-61.

22. Neideen T, Lam M, Brasel KJ. Preinjury beta blockers are associated with increased mortality in geriatric trauma patients. J Trauma Acute Care Surg. 2008;65(5):1016-20.
23. Wang T, Woodhead A, Pemberton J, Ramanathan T. Relationship between beta-blockers and mortality in diabetic patients undergoing coronary artery bypass grafting. Heart Lung Circ. 2015;24:S105.

24. Tsujimoto T, Sugiyama T, Kajio H. Effects of beta-blockers on all-cause mortality in patients with type 2 diabetes and coronary heart disease. Diabetes Obes Metab. 2017;19(6):800-8.

\section{Ready to submit your research? Choose BMC and benefit from:}

- fast, convenient online submission

- thorough peer review by experienced researchers in your field

- rapid publication on acceptance

- support for research data, including large and complex data types

- gold Open Access which fosters wider collaboration and increased citations

- maximum visibility for your research: over $100 \mathrm{M}$ website views per year

At BMC, research is always in progress.

Learn more biomedcentral.com/submissions 